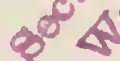

(Septerne 6,1927 )

\title{
RELDUSPIIGSCPEW-KNOB WIGHTS
}

\section{OCIISS S}

occasionally, after a set of Class $S$ screw-knob weights has beer examinea for the efiect of changes in the humiaity of the atmosphere, one on two of the weirits are found to be outsicie tile tolerance and trius tiey car nut be certified. In such cases, the time reouirea for readjusting the inaccurate weishts will usually be less tien tiat involved in returning them and later putting replaceineit weights trrough a humidity test. The reaajustment of such wejihts by tinis Bureau may therefore conserve the tine of tre Bureau as well as save expense for those wino submit weichts.

Therefore the Eureali is prepared to äo such readjusting, except where sone peculiarity of the weicht or some other unusual circumstance manes it inadvisable to do so. Those who wish to do so may Ieave a standing order for the Bureau to a such reaijusting on veights submitted by them. In other cases the parter involved will be notified and tre weishts will be hela urtil definite inzormation is received.

Sheet inetal weigts (those below I gram) are not examined for the effect of inumidity, ano therefore the reporting and 

ruplacement of such weights will be hanaled the same as heretorore.

For weignts tire actual corrections of wich are to be aetermined, a special fee ö $\$ 2.00$ per weight has been tentatively acioptea to covor both the readjustuent and the final certification; for weights to be given the tolerance test this fee rill be pl.65 per veight. Fur one or two weights, these fees amount to less tian tile fees for the testing of the weights sent to replace tife inaccucate ones. For 3 weignts twese fees arlount to somerhat isore than the fees for testing rew weisits, but the total cost to the party submitting them is probably less on account of the saving of transportation charses and time involved in wakine tie readjustrnents.

For 4 wints or more it is doubtul whether any sood purpose is subserved by tre plan and ordinarily, therciore, tils reacjustinent will bo limited to not more than 3 meights in any récular sət. 


